\title{
Optimal Control Model for Vaccination Against H1N1 Flu
}

\section{Modelo com Controle Ótimo para a Vacinação contra a Gripe H1N1}

\author{
Pablo Amauri Carvalho Araújo e Souza ${ }^{1}$; Claudia Mazza Dias²; \\ Edilson Fernandes de Arruda ${ }^{3}$
}

\begin{abstract}
This paper introduces a mathematical model to describe the dynamics of the spread of H1N1 flu in a human population. The model is comprised of a system of ordinary differential equations that involve susceptible, exposed, infected and recovered/immune individuals. The distinguishing feature in the proposed model with respect to other models in the literature is that it takes into account the possibility of infection due to immunity loss over time. The acquired immunity comes from self-recovery or via vaccination. Furthermore, the proposed model strives to find an optimal vaccination strategy by means of an optimal control problem and Pontryagin's Maximum Principle.
\end{abstract}

Keywords: Optimal control. Mathematical modeling. Pontryagin's maximum principle. H1N1 flu. Vaccination.

\section{Resumo}

Este artigo apresenta um modelo matemático para descrever a dinâmica da propagação da gripe H1N1 em uma população humana. $\mathrm{O}$ modelo é composto por um sistema de equações diferenciais ordinárias que envolvem indivíduos suscetíveis, expostos, infectados e recuperados / imunes. O modelo se diferencia dos demais na literatura por levar em consideração a possibilidade de infecção devido à perda de imunidade ao longo do tempo. A imunidade pode ser adquirida naturalmente, ao convalescer da doença, ou por meio de vacina. Além disso, o modelo proposto busca encontrar uma estratégia de vacinação ideal por meio de um problema de controle e do Princípio Máximo de Pontryagin.

Palavras-chave: Controle ótimo. Modelagem matemática. Princípio do máximo de Pontryagin. Gripe H1N1. Vacinação.

\footnotetext{
${ }^{1}$ Doutorando, Inst. Alberto Luiz Coimbra de Pós Grad. e Pesq. de Eng., UFRJ, RJ, Brasil, E-mail: pablocaeso@ gmail.com

2 Profa. Dra., Prog. Pós Grad. em Modelagem Matem. e Comp., UFRRJ, Nova Iguaçu, RJ, Brasil, E-mail: mazzaclaudia@ gmail.com

${ }^{3}$ Prof. Dr., Inst. Alberto Luiz Coimbra de Pós Grad. e Pesq. de Eng, UFRJ, Rio de Janeiro, RJ, Brasil, E-mail: efarruda@ pep.ufrj.br
} 


\section{Introduction}

Some diseases are known to return periodically over time, such as the common cold and the H1N1 flu, and modellers often employ epidemiological models to study their behaviour. The H1N1 flu, in particular, spreads very rapidly and has been a concern to Brazilian public health officials since the first outbreak in 2009. It returned with particular force in 2016, uncharacteristically long before wintertime, and that has led to the anticipation of the annual vaccination campaign.

Given the spread of the disease and its potential to return in short time spans, models and tools to assist both in the understanding of the dynamics and in the design of control mechanisms for the H1N1 flu gained renewed importance (BANKER; WILSON, 2009; OLIVEIRA et al., 2009). To evaluate the strategy taken by the Korean government to overcome the epidemic, Kim et al. (2017) addressed three types of control and analysed the intervention taken by the Republic of Korea in the 2009 outbreak. Earlier, a model with agedependent transmission rates was introduced in Lee et al. (2013). In another study, researchers addressed flu-like pandemics and modelled vaccination and antiviral controls, splitting the infected compartment into two: infected who are untreated $\left(I_{u}\right)$ and infected who are treated $\left(I_{t r}\right)$ (LEE; CHOWELL, 2017). Other studies applying control theory to influenza vaccination problems can be found in (JABERI-DOURAK; MOGHADAS, 2014; TCHUENCHE et al., 2011). Unlike the present work, however, the aforementioned studies do not contemplate the possibility of reinfection. From the logistics standpoint, an optimal vaccine distribution model for the influenza virus (H5N1) was introduced in Matrajt et al. (2013) and solved by means of genetic algorithms.

As one might expect, optimal control strategies are not exclusively applied to the control of influenza or flu-like pandemics. In Malik et al. (2013) one is faced with a study regarding three types of plurivalent vaccines against the human papillomavirus (HPV), which considers distinct dynamics for women and men. Outside pandemic models, optimal control strategies can be used to study drug administration in HIV treatment (PASTORE et al., 2018; ARRUDA et al., 2015). In addition, a variety of optimal control strategies in biological mathematical models can be found in the literature, see for example (FATMAWATI; TASMAN, 2015; HELAL et al., 2015; NANNYONGA et al., 2015; TAI et al., 2015).
This paper proposes a mathematical model based on differential equations to describe the dynamics of the H1N1 flu. In addition, we develop an optimal control problem to find an optimal vaccination strategy over a prescribed time horizon, in such a way as to prevent contagion while keeping the overall cost of the vaccination campaign to a minimum. It is worth pointing out that finding an adequate criterion to contrast the financial costs of vaccination campaigns with the social cost of the spread of the disease may not be a trivial test for policy makers. Indeed, delving into this problem is besides the scope of the present paper. One may argue, however, that the spread of the disease does imply a financial cost, which may be used in the design of the vaccination strategy. The main contributions of this paper are twofold. Firstly, we treat the control action weights in the cost functional as parameters (monetary cost), which can be modified in numerical simulations and sensitivity analyses. Secondly, in contrast to the literature on H1N1 control strategies, the proposed model allows for the possibility of reinfection, thus enabling the policy maker to account for the seasonal nature of the virus. All in all, the paper calls for a new dialogue between the scientific community and the policy makers, offering insight into the efficacy of control and prevention in times of scarce investments.

More specifically, this paper addresses a mathematical formulation comprising a set of ordinary differential equations based on the so-called Susceptible - Infected - Removed (SIR) model. This model, proposed by Kermack and McKendric (1927), is comprised of a non-linear system of equations that describe each of the subgroups included in the model: the susceptible, which are individuals vulnerable to the disease; the infected, those that actually had contracted it and may infect others; and the removed, which comprises two groups of individuals, those already recovered and considered immune to the disease for some time thereafter and those who died from the disease (KERMACK; MCKENDRIC, 1927). The proposed formulation considers the possibility of vaccination, which influences the dynamics of the disease by preventing contagion. The vaccination, however, may lose efficiency over time, occasioning the possibility of reinfection for vaccinated individuals; such loss of efficiency is modelled by a parameter. This paper also addresses the problem of generating an optimal vaccination strategy in terms of a cost functional, which takes into account the vaccination cost and a cost related to the number of infected individuals. 
The proposed problem is modelled as an optimal control problem, and solved by an iterative procedure based on the gradient algorithm (KIRK, 1970).

\section{The vaccination process}

The importance of the use of vaccination as a protection against disease may be based on two components: a decrease in the number of new cases (morbidity) and the low financial cost of the vaccine in relation to the treatment of the disease. The goal is to induce a protection against the pathogen not only to safeguard individuals against serious forms of the disease, but also to control the disease in the community. Therefore, a thorough understanding of the effects of vaccination on the community requires more than pure biological knowledge. To attain it, one should consider the effect of vaccinating individuals, in order to come up with a strategy that interrupts the chain of disease transmission. In that context, mathematical models can be very useful, providing contributions to the understanding of the underlying dynamics. Such models describe the phenomenon of disease transmission and allow the generation of scenarios from different vaccination strategies, thus anticipating the effects of an eventual vaccination.

The vaccine production process for an arising flu strain requires at least 6 months for virus identification, vaccine invention, and then mass production using a long-standing egg-based technology (LARSON; TEYTELMAN, 2012). According to the Brazilian government, egg allergy is the single counter indication of this manufacturing technology. In any case, in addition to side effects, there are other factors which are critical to the effectiveness of vaccination strategies. It is understood that the vaccine may fail in two levels. Firstly, it may not induce immunity in the individual, typically as a result of some failure in the manufacturing process or of some deficiency in the individual's immune system. Failure may also occur when the level of vaccination immunity is low, therefore resulting in immunity loss shortly after taking the vaccine. This illustrates the importance of incorporating the possibility of reinfection in the vaccination model.

To understand the role of vaccination in the eradication of a disease, we must define two basic concepts in epidemiology. The first is called force of infection, which corresponds to a per capita disease incidence or incidence of new cases per susceptible individual in a population. The force of infection could determine not only the extent of the spread but also the necessary effort to stop it.
The second concept is the most important parameter in epidemiology, the reproductive number $R_{0}$, defined as the average number of new infections per infected individual in a fully susceptible population. If $R_{0}<1$ the disease will be extinguished, while $R_{0}>1$ implies that the disease is endemic. The value of $R_{0}$ is an indication of the severity of the epidemic; the higher the value, the more severe the situation.

By vaccinating individuals, one often expects to slow down the spread of the disease by turning susceptible individuals into immune ones whilst also preventing them from acquiring the disease. As a consequence, one can also expect a decrease in secondary cases generated by infected individuals, thus creating a chain effect that benefits the population and reduces the reproductive number $R_{0}$. Hence, one can view vaccination as a control mechanism for the disease. Under such a view, this paper studies the effect of vaccination on the spread of H1N1 flu. The model also accounts for reinfection, with a view at emulating the effect of weakened immunity as the time elapsed since the last vaccination increases.

This work is organised as follows. The following section explains the nature of compartment model, upon which our Optimal Control Problem is based. Next, we introduce the optimal control problem, employ Pontryagin's maximum principle to find an optimal vaccination strategy and derive the equilibrium points for the proposed model. Then, in order to illustrate the proposed approach, we present 4 (four) distinct numeric simulations. Each simulation depicts the resulting optimal vaccination campaign, as well as the population dynamics as the campaign progresses. Finally, the last section concludes the paper.

\section{The model}

Influenza is a directly transmitted disease, i.e., its spread occurs following the contact of susceptible individuals (who have not had contact with the virus) with infected individuals (who have non-negligible concentration of virus in their bodies). A mathematical formulation comprises a set of ordinary differential equations that describe the so-called Susceptible - Infected - Removed (SIR) model, where $S$ represents susceptible individuals, $I$ stands for infected patients and $R$ corresponds to removed individuals. The compartmentalised model, widely used to study the transmission dynamics of infectious diseases, including H1N1 flu (DIAS; ARRUDA, 2014; DIAS et al., 2015), assumes that an individual may successively visit stages of susceptibility, infection and recovery (removal). 
It also assumes that immunity is permanent (for life). Generally, the model does not consider the latency period during which the virus replicates in the cells of the newly infected individual, i.e. it does not consider infected but not infectious individuals. Additionally, the rates of birth and death are equal, which implies that the population has reached equilibrium. The model also has the limitation of considering that individuals are evenly spread in space. However, this assumption makes sense if one wishes to describe the spread of a disease in a population spatially distributed by means of differential equations.

In this study we consider two improvements in the SIR model, firstly, we consider that part of the susceptible population has either been vaccinated or has already recovered from the infection, and therefore is partially protected from the complications arising from the disease. This effect will be introduced in the next section by means of the variable $u(t)$, that emulates the vaccination strength at any given time $t$. The optimal vaccination strength levels will then be determined by means of an optimal control variable. Secondly, we consider that the vaccine has limited effect and that after a period of time there is the possibility of reinfection. To that effect, we introduce the group $E$ that represents the number of exposed or latent individuals at time $t$, and $R$ is now the number of recovered individuals at time $t$. The system of equations in (1) represents the evolution of population in time,

$$
\begin{aligned}
& \frac{d S}{d t}=\alpha+\zeta R-\beta I S-\mu S \\
& \frac{d E}{d t}=\beta I S-\kappa E-\mu E \\
& \frac{d I}{d t}=\kappa E-\delta I-\gamma I-\mu I \\
& \frac{d R}{d t}=\gamma I-\zeta R-\mu R .
\end{aligned}
$$

In the system of equations (1), $\alpha$ is the rate of birth or immigration; $\beta$ is the infection rate of susceptible individuals upon contact with infected individuals; $\mu$ is the natural death rate; $\kappa$ is the infection rate for exposed individuals; $\delta$ is the rate of disease-induced death; $\gamma$ is the rate of recovery from the disease. The dynamics of the proposed model is depicted in Figure 1. Note that $S(t)+E(t)+I(t)+$ $R(t)=N(t)$, where $N(t)$ is the total population. Observe also that $1 / \kappa$ days is the average length of the latent period, and $1 / \gamma$ days is the mean length of the infectious period before recovery (LENHART; WORKMAN, 2007).
Typically, the parameters in (1) can be inferred from real data by means of statistical methods (MAGALHÃES et al., 2016). As vaccine-induced immunity weakens over time, it is necessary to consider the rate of immunity loss $\zeta$, where $\zeta=0$ means perennial immunity. For the sake of simplicity we define variable $X(t)=\{S(t), E(t), I(t), R(t)\}$ to represent the set of all variables of the original system.

Figure 1 - Transfer diagram of the Influenza A (H1N1) epidemic model with reinfection.

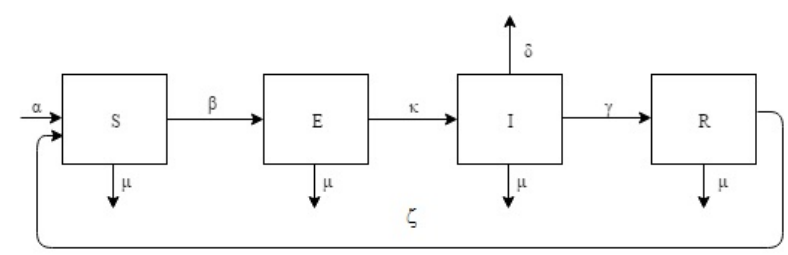

Source: The authors.

\section{The optimal control problem}

The rationale of the optimal control formulation in this section is to search for a vaccination strategy with the ideal compromise between vaccination cost and the resulting protection level. Such a compromise must be built upon the fact that a full vaccination of the population is generally unnecessary from a immunization standpoint; in addition, it is often infeasible from a logistics point of view. The system below describes the dynamics of the controlled system, considering the effects of vaccination. The interactions between the variables are depicted in Figure 2 that follows.

$$
\begin{aligned}
& \frac{d S}{d t}=\alpha+\zeta R-\beta I S-\mu S-u S \\
& \frac{d E}{d t}=\beta I S-\kappa E-\mu E \\
& \frac{d I}{d t}=\kappa E-\delta I-\gamma I-\mu I \\
& \frac{d R}{d t}=\gamma I-\zeta R-\mu R+u S
\end{aligned}
$$

The variable $u(t)$ is the portion of susceptible individuals that must be vaccinated at each time interval, and comprises the vaccination strategy. Each dose of vaccine has a cost, and typically a higher vaccination covering implies in a non-linear cost increase due to the increased logistic requirements to reach remote populations. 
Figure 2 - Transfer diagram of the Influenza A (H1N1) epidemic model with reinfection and vaccine control.

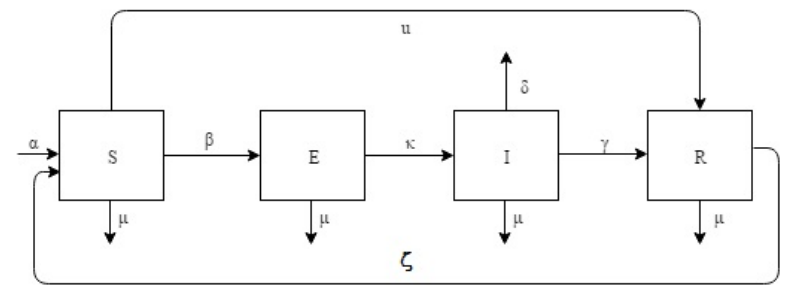

Source: The authors.

In our model, we use a quadratic cost function to represent the overall vaccination budget. Naturally, we also aim to protect the largest possible number of individuals, which is equivalent to minimising the number of infected individuals, that also composes the cost functional. Hence, for any control trajectory $u: t \rightarrow \mathbb{R}_{+}$, we define the cost functional $J[u]$ as

$$
J[u]=\min \int_{0}^{T}\left(I(t)+c u(t)^{2}\right) d t
$$

where $c \geq 0$. While the cost functional in (3) accounts for our objectives, it may lead to infeasible solutions, prescribing infinite vaccination rates at the origin, to make sure the number of infected individuals is nil. Since it is obvious that the vaccination effort is limited, we define a normalized rate of vaccination $u: t \rightarrow[0,1]$. For calculation purposes, we make a small change in the cost functional, replacing the control variable $u(t)$ for an equivalent variable $v(t)=1-u(t)$, which leads to:

$$
J[v]=\min \int_{0}^{T}\left(I(t)+c(1-v(t))^{2}\right) d t .
$$

The above formulation, with the constant $v(t) \geq 0$, ensures that the vaccination levels $u(t)$ are normalized in the interval $[0,1]$.

To solve the optimal control problem we make use of Pontryagin's Maximum Principle (PMP) (FLEMING; RISHEL, 1975) and derive the Hamiltonian of the problem, given by:

$$
\begin{aligned}
& H=I+c(1-v)^{2}+w_{1}[\alpha+\zeta R-\beta I S-\mu S- \\
& +(1-v) S]+w_{2}[\beta I S-\kappa E-\mu E]+w_{3}[\kappa E- \\
& +\delta I-\gamma I-\mu I]+w_{4}[\gamma I-\zeta R-\mu R+(1-v) S]+ \\
& +z v
\end{aligned}
$$

where $W(t)=\left\{w_{1}, w_{2}, w_{3}, w_{4}\right\}$ is the set of adjoint variables, or Lagrange multipliers. The PMP also states that there must exist a differential relation between original system and the associated vari- ables in the adjoint system, given by $\frac{d W}{d t}=-\frac{\partial H}{\partial X}$. Hence, the adjoint system of equation becomes:

$$
\begin{aligned}
\frac{d w_{1}}{d t} & =\frac{d H}{d S}=w_{1}(\beta I+\mu+1-v)-w_{2} \beta I-w_{4}(1-v) \\
\frac{d w_{2}}{d t} & =\frac{d H}{d E}=w_{2}(\kappa+\mu)-w_{3} \kappa \\
\frac{d w_{3}}{d t} & =\frac{d H}{d I}=-1+w_{1} \beta S-w_{2} \beta S+ \\
& +w_{3}(\delta+\gamma+\mu)-w_{4} \gamma
\end{aligned}
$$$$
\frac{d w_{4}}{d t}=\frac{d H}{d R}=w_{4}(\zeta+\mu)-w_{1} \zeta
$$

The system (6) has a final boundary condition, called transversatility condition, $w_{i}(T)=0$, where $i=1, \ldots, 4$ and $T$ is the final optimization horizon.

\section{Solving the optimal control problem}

Now we have two differential equations systems to solve. For the original system in (2) we typically have the initial conditions, whereas the adjoint equations in (6) must satisfy the final boundary condition. To solve both systems we applied the Finite Differences Method (FDM), with forward and backward differences respectively (BURDEN; FAIRES, 2008).

\section{The equilibrium of the proposed model}

To study the equilibrium of the original system without any interference we must assume that no vaccination (control) is applied. In other words, we must consider the uncontrolled system (1). When the system reaches equilibrium, we must have $\frac{d X}{d t}=0$, and it is that expression that enables us to find the composition of the population at equilibrium.

As mentioned below, it is of the utmost importance that we determine the reproduction number $R_{0}$. To perform this we define $s(t)=\frac{S(t)}{N(t)}$, which represents the fraction of susceptible individuals in the population. So, stationary equilibrium implies $\frac{d s}{d t}=0$. Consequently, we must have:

$$
s\left(t_{e q}\right)=\frac{(\delta+\gamma+\mu)(\kappa+\mu)}{\beta \kappa},
$$

where $t_{e q}$ is the time to reach equilibrium. For the other groups, exposed; infected and recovered, their respective 
ratios in equilibrium are:

$$
\begin{gathered}
e\left(t_{e q}\right)=\frac{(\delta+\gamma+\mu)(\zeta+\mu)\left(R_{0} \alpha-\mu\right)}{(\zeta+\mu) \beta \kappa-R_{0} \zeta \gamma \kappa}, \\
i\left(t_{e q}\right)=\frac{(\zeta+\mu)\left(R_{0} \alpha-\mu\right)}{(\zeta+\mu) \beta-R_{0} \zeta \gamma} \\
r\left(t_{e q}\right)=\frac{\gamma\left(R_{0} \alpha-\mu\right)}{(\zeta+\mu) \beta-R_{0} \zeta \gamma}
\end{gathered}
$$

Observe that $X(t)=X\left(t_{e q}\right) \forall t \geq t_{e q}$. So we can calculate $s\left(t_{e q}\right)$, and consequently determine $R_{0}$ :

$$
R_{0}=\frac{\beta \kappa}{(\delta+\gamma+\mu)(\kappa+\mu)}
$$

\section{Numerical solutions}

This section features some simulations, performed in a new code developed in MATLAB ${ }^{\complement}$ R2016a, that considers variations of two parameters: vaccination cost and initial infected population $(I(0))$. For all simulations, we consider the set of parameters in Table 1.

Table 1 - General simulations parameters

\begin{tabular}{cc}
\hline Parameter & Value \\
\hline$\alpha$ & 1 individuals per day \\
$\beta$ & 0.00018 \\
$\kappa$ & 0.3333 individuals per day \\
$\delta$ & 0.001 individuals per day \\
$\gamma$ & 0.14 individuals per day \\
$\mu$ & 0.0000548 individuals per day \\
$\zeta$ & 0.0333 individuals per day \\
$T$ & 100 days \\
\hline
\end{tabular}

Source: The authors.

With the exception of the rate of immunity loss $(\zeta)$, all parameters in Table 1 were borrowed from (ZHOU; GUO, 2012). The choice of $T=100$ days is directly associated with the duration of brazilian vaccination campaign and $\zeta=0.0333$ implies a slow rate of immunity loss. All simulations start with a healthy but susceptible population that receives one or more infected individuals.

Table 2 displays the data of all four simulation cases

\begin{tabular}{|c|c|c|c|c|}
\hline Parameter & (I) & (II) & (III) & (IV) \\
\hline$S(0)$ & 1000 & 1000 & 1000 & 1000 \\
\hline$E(0)$ & 0 & 0 & 0 & 0 \\
\hline$I(0)$ & 1 & 5 & 5 & 10 \\
\hline$R(0)$ & 0 & 0 & 0 & 0 \\
\hline Strategy cost(c) & 10 & 10 & 80 & 80 \\
\hline Accuracy x $10^{-4}$ & 1 & 1 & 5 & 7.5 \\
\hline \multicolumn{5}{|c|}{ Comput. informations } \\
\hline Iterations & 50 & 155 & 38 & 60 \\
\hline Exec. time(s) & 0.3594 & 0.9219 & 0.1875 & 0.3596 \\
\hline
\end{tabular}
featured in this section, as well as the computational output, which is displayed in the bottom part of the table.
Table 2 - Experimental Parameters

Source: The authors.

For all examples, we set the initial susceptible population $(S(0))$ to a thousand individuals, whereas the exposed and immune population $(E(0)$ and $R(0)$, respectively) are both nil. For experiment (I), the initial infected population $I(0)$ is set to one and the cost parameter $c$ is set to 10 . For the remaining cases, these parameters are alternately changed, as detailed in Table 2. Accuracy refers to the tolerance used as a reference for the convergence of the computational method.

Figures 3-6 depict the results. They show the evolution of susceptible, infected and recovered populations as time elapses, as well as the optimal vaccination strategy $u$. Figure 3 features experiment (I), which simulates the introduction of a single H1N1 infected individual in a healthy population, with a vaccination strategy $\operatorname{cost}(c=10)$. Note that the optimal strategy prescribes an immediate vaccination rate of $u(0)=0.33$ and decreases such a rate as time progresses. Observe also that the infection is rapidly eradicated, whereas the immune population grows steeply to the totality of individuals.

In the second experiment (Figure 4) we increase the initial infected population, and that has an impact in the initial rate of vaccination, which increases to around 0.84 . Such a control manages to keep the infected, susceptible and immune populations over time in similar levels to those in the Experiment (I).

The results of Experiment (III), which features a significant increase in the vaccination $\operatorname{cost} c$, are presented in Figure 5. That results in a decrease of the initial vaccination rate to around 0.23 . Once again, the infected, susceptible and immune populations are kept in similar levels to those in the Experiment (I). 
Figure 3 - Experiment (I) results. Optimal vaccination strategy (a); susceptible individuals dynamics (b); infected individuals dynamics (c); immune individuals dynamics (d).

(a)

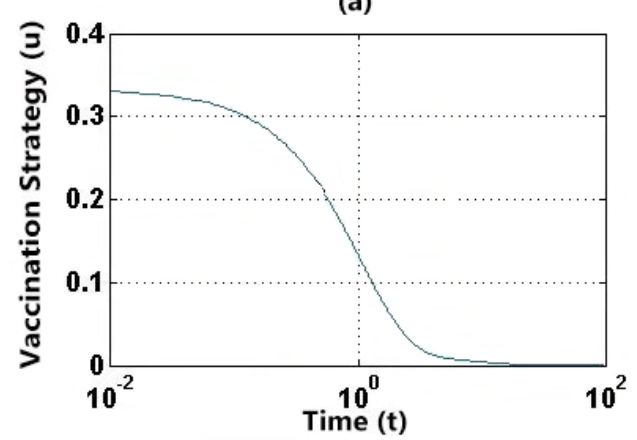

(c)

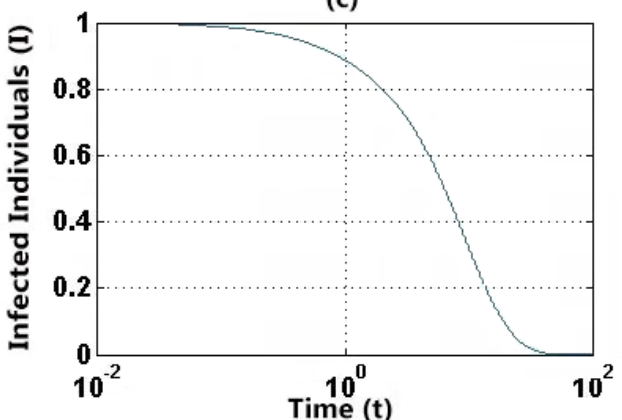

(b)

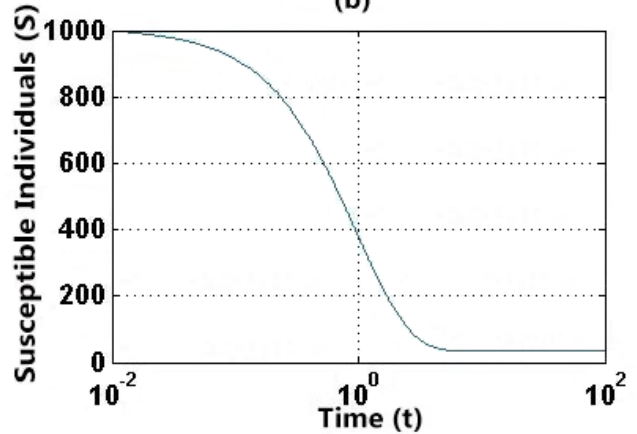

(d)

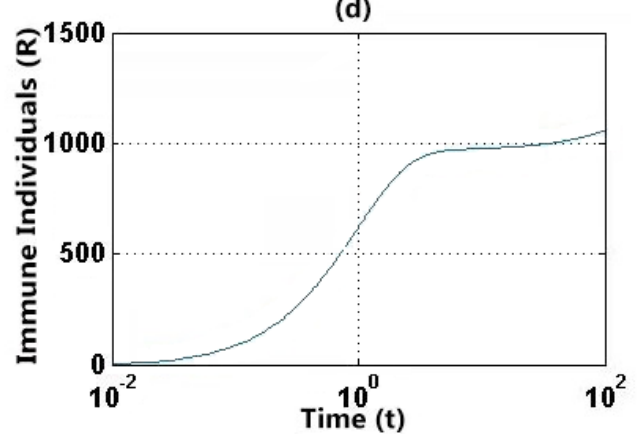

Source: The authors

Figure 4 - Experiment (II) results. Optimal vaccination strategy (a); susceptible individuals dynamics (b); infected individuals dynamics (c); immune individuals dynamics (d).

(a)

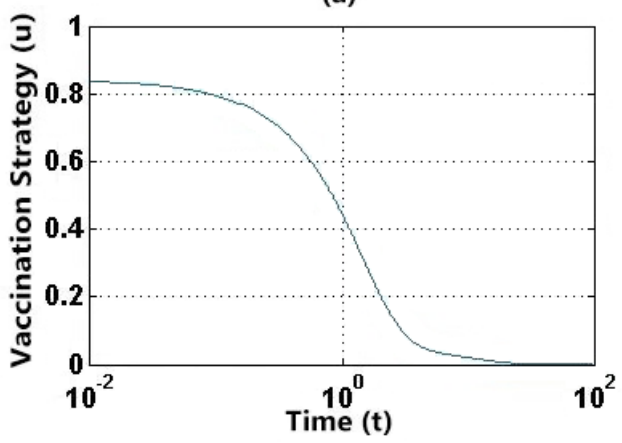

(c)

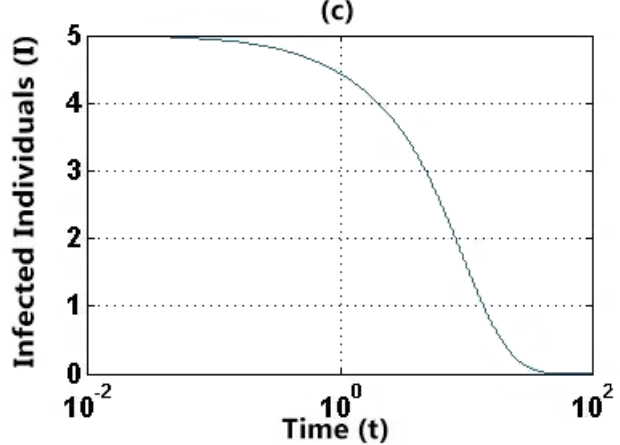

(b)

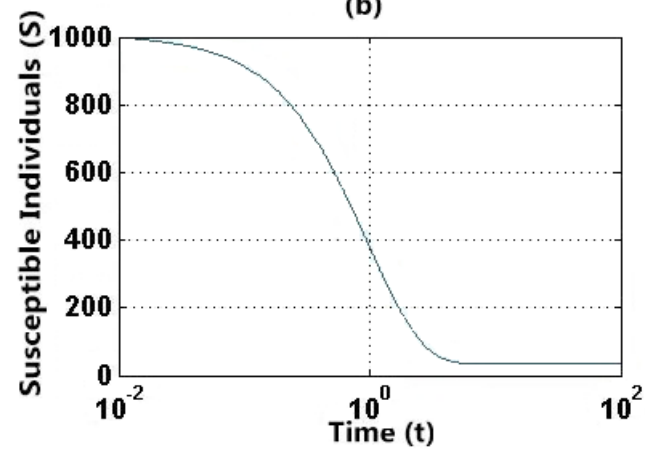

(d)

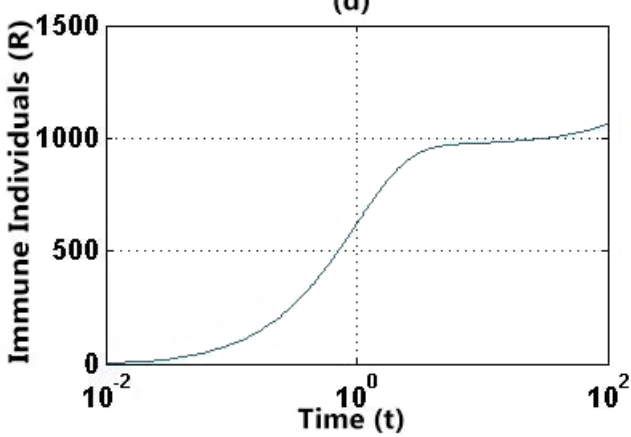

Source: The authors 
Figure 5 - Experiment (III) results. Optimal vaccination strategy (a); susceptible individuals dynamics (b); infected individuals dynamics (c); immune individuals dynamics (d).

(a)

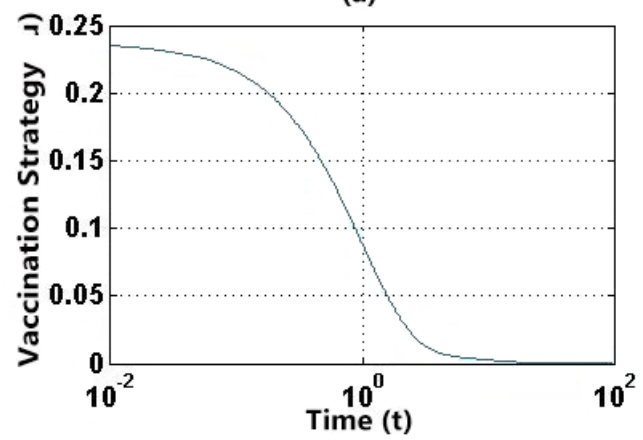

(c)

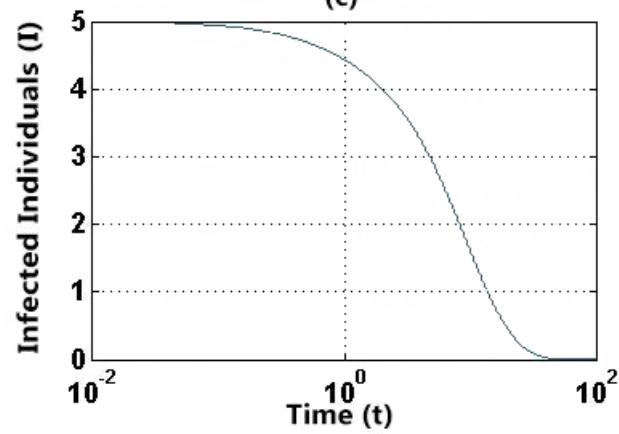

(b)

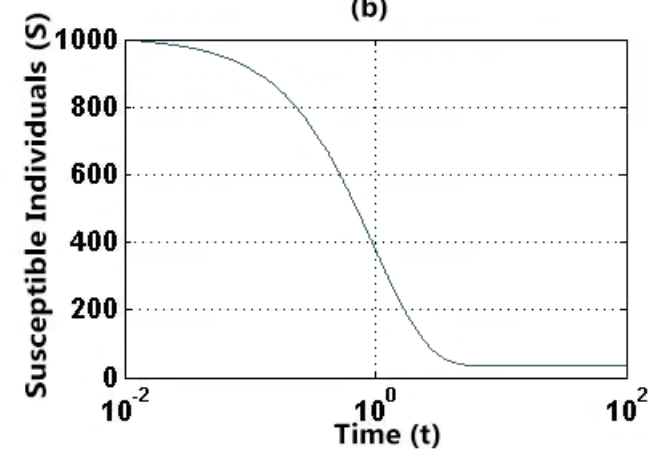

(d)

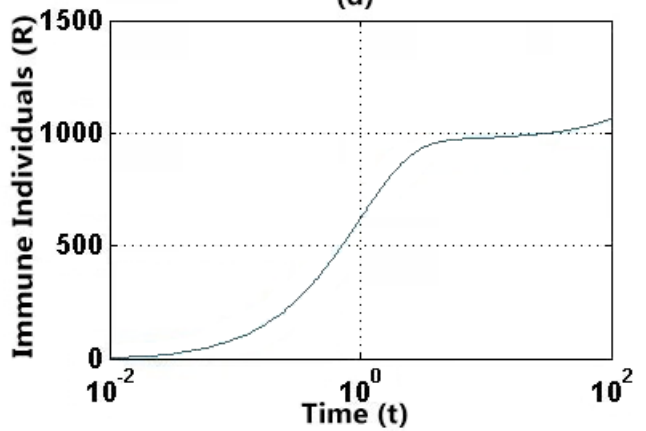

Source: The authors.

Figure 6 - Experiment (IV) results. Optimal vaccination strategy (a); susceptible individuals dynamics (b); infected individuals dynamics (c); immune individuals dynamics (d).

(a)

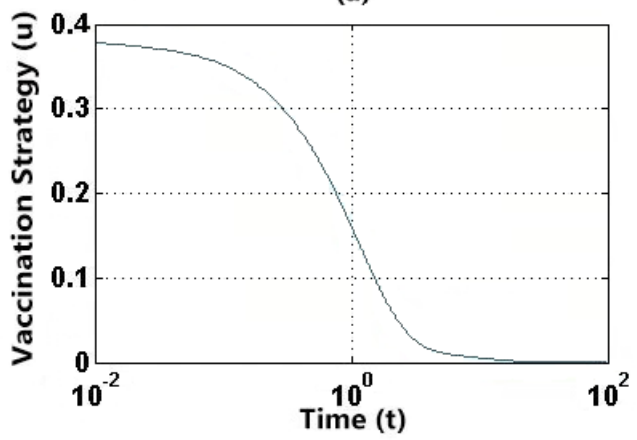

(c)

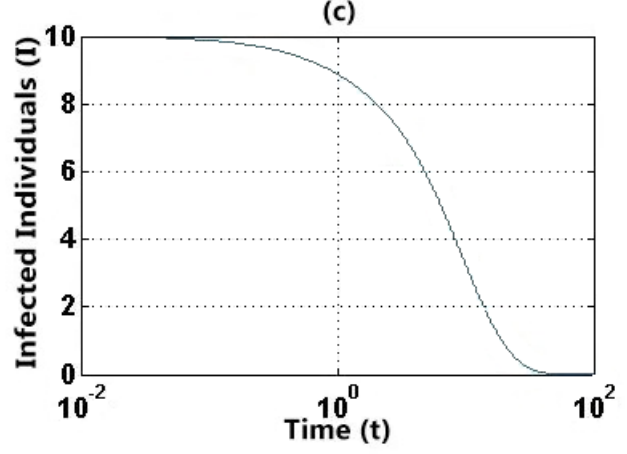

(b)

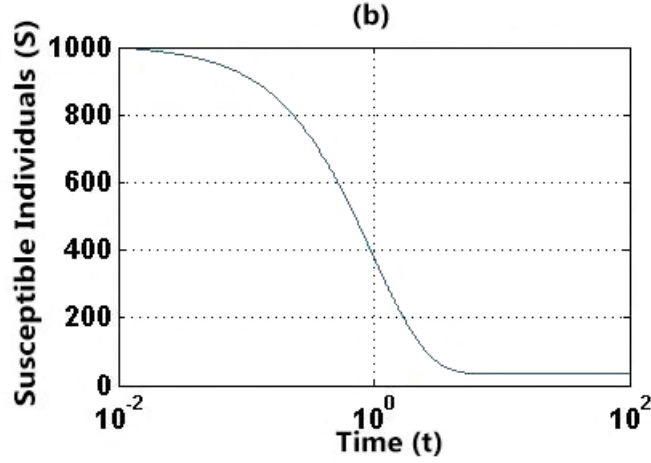

(d)

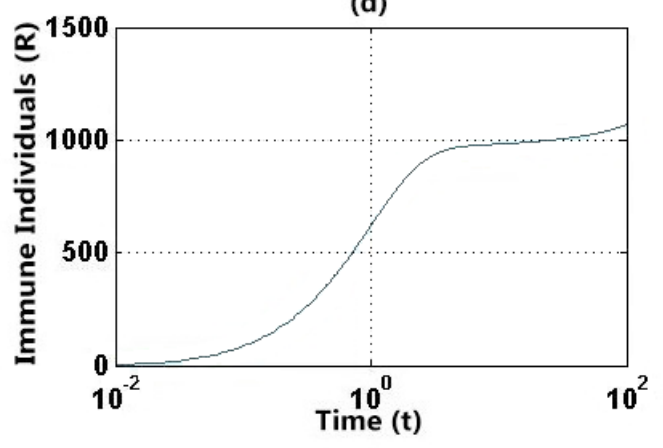

Source: The authors. 
The results of Experiment (IV) are depicted in Figure 6. The infected population is increased with respect to that of the previous experiment, representing around $1 \%$ of the healthy population. That results in an increase in the initial vaccination rate to around 0.38 , and the new strategy manages to keep all populations in similar levels to those in the previous experiments.

It is worth pointing out that in all simulations the optimal control problem leads the infection to zero around the middle of simulated period. This fact means that the optimal control achieves the desired prevention, blocking the virus spread while accounting for the monetary cost of the vaccination strategy.

\section{Concluding Remarks}

It is known that naturally created immunity for infection and immunity induced by vaccination are not permanent. They reduce over time causing a significant impact on immunisation programs. We employ a model that takes into account the immunity loss over time. Vaccines can be used to control or eradicate a disease. If the goal is the eradication, the knowledge concerning the immunisation period of a vaccine must be complete. Thus, eradication strategies based on vaccination will only be effective if the protection time is long enough. Specifically regarding Influenza, that poses a great challenge. We proposed an optimal control problem to retrieve an optimal vaccination for a prescribed period, taking into account the immunity loss that leads to reinfection. The obtained results are promising and suggest that the model is sound and can be helpful in the design of public policies under budgetary constraints, and to track vaccination goals.

\section{Acknowledgments}

This study was financed in part by the Coordenação de Aperfeiçoamento de Pessoal de Nível Superior - Brasil (CAPES) - Finance Code 001, and was partially supported by the National Council for Scientific and Technological Development - CNPq, under grant 311075/2018-5.

\section{References}

ARRUDA, E. F.; DIAS, C. M.; MAGALHÃES, C. V. M.; PASTORE, D. H.; THOMÉ, R. C. A.; YANG, H. M. An optimal control approach to HIV immunology. Applied Mathematics, New York, v. 6, p. 1115-1130, 2015.
BANKER, M. G.; WILSON, H. K. Pandemic H1N1 influenza lessons from the southern Hemisphere. Eurosurveillance, Stockholm, v. 14, n. 42, p. 19370, 2009.

BURDEN, R. L.; FAIRES, J. D. Numerical analysis. 2. ed. Massachusetts: Cengage Learning, 2008.

DIAS, A. C.; ARRUDA, E. F.; SOUZA, P. A. C. A. A study for computational cost optimization for influenza flu including vaccination's impact. In: CONGRESS OF NUMERICAL METHODS IN ENGINEERING, 2015, Portugal. Proceedings [...].Lisboa: CMNE, 2015. p. 116.

DIAS, C. M.; ARRUDA, E. F. Computational cost optimization for influenza A (H1N1) epidemic model. In: INTERNATIONAL CONGRESS ON ENV. MODELLING AND SOFTWARE, 7., 2014, San Diego. Proceedings [...].San Diego: IEMSS, 2014. p. 1 - 8.

FATMAWATI, H.,TASMAN, H., An optimal control strategy to reduce the spread of malaria resistance. Mathematical Biosciences, New York, 262, 73-79, 2015.

FLEMING, W., RISHEL, R., Deterministic and stochastic optimal control.New York, Springer-Verlag, 1975.

HELAL, Z. A., REHBOCK, V., LOXTON, R., Modelling and optimal control of blood glucose levels in the human body. Journal of Industrial and Management Optimization, United States, v. 11, n. 4, p. 1149-1164, 2015.

JABERI-DOURAK, M., MOGHADAS, S. M., Optimal control of vaccination dynamics during an influenza epidemic. Mathematical Biosciences and Engineering, Springfield, v. 11, n. 5, p. 1045-1063, 2014.

KERMACK, W. O., MCKENDRIC, A. G., A contribution to the mathematical theory of epidemics. Royal Soc. London Proc. Series., London, A115, p. 700-721, 1927.

KIM, S., LEE, J., JUNG, E., Mathematical model of transmission dynamics and optimal control strategies for 2009 A/H1N1 influenza in the Republic of Korea. Journal of Theoretical Biology, London, v. 412, p. 74-85, 2017.

KIRK, D., Optimal control theory: an introduction. New Jersey: Prentice-Hall, 1970.

LARSON, R. C.; TEYTELMAN, A. Modeling the effects of H1N1 influenza vaccine distribution in the United States. Value in Health, New York, v. 15, p. 158-166, 2012. 
LEE, J.; KIN, J. ; KWON, H-D. Optimal control of an influenza model with seasonal forcing and age-dependent transmission rates. Journal of Theoretical Biology, Amsterdam, v. 317, p. 310-320, 2013.

LEE, S.; CHOWELL, G. Exploring optimal control strategies in seasonally varying flu-like epidemics. Journal of Theoretical Biology, Amsterdam, v. 412, p. 36-47, 2017.

LENHART, S.; WOKMAN, J. T. Optimal control Applied to Biological Models. [London]: Chapman \& Hall, 2007.

MAGALHÃES, S. R. S.; VEIGA, R. D.; SÁFADI, T.; CIRILLO, M. A.; MAGINI, M. Avaliação de métodos para comparação de modelos de regressão por simulação de dados. Semina: Ciências Exatas e Tecnológicas, Londrina, v. 25, n. 2, p. 117-122, 2004.

MALIK, T., IMRAN, M., JAYRAMAN, R., Optimal control with multiple human papillomavirus vaccines. Journal of Theoretical Biology, London, v. 393, p. 179-193, 2016.

MATRAJT, L. ; HALLORAN, M. E.; LONGINI JUNIOR, I. M. Optimal vaccine allocation for the early mitigation of pandemic influenza. PLOS Computational Biology, San Francisco, v. 9, n. 3, 2013.

NANNYONGA, B.; MWANGA, G. G.; LUBOOBI, L. S. An optimal control problem for ovine brucellosis with culling. Journal Of Biological Dynamics, Abingdon, v. 9, p. 198-214, 2015.
OlIVEIRA, W. K.; HAGE, E. C.; PENNA, G. O.; KUCHENBECKER, R. S.; SANTOS, H. B.; ARAÚJO, W. N. Pandemic H1N1 influenza in Brazil: analysis of the first 34,506 notified cases of influenza-like illness with severe acute respiratory infection (SARI). Euro Surveill, Saint-Maurice, v. 14, n. 42, p. 1-6, 2009.

PASTORE, D. H.; THOMÉ, R. C. A.; DIAS, C. M.; ARRUDA, E. F.; YANG, Y. M. A model for interactions be- tween immune cells and HIV considering drug treatments. Computational and Applied Mathematics, Petrópolis, v. 37, p. 282-295, 2018.

TAI, C.; KESHWANI, D. R.; VOLTAN, D. S.; KUHAR, P. S.; ENGE, A. J. Optimal Control Strategy for Fed-Batch Enzymatic Hydrolysis of Lignocellulosic Biomass Based on Epidemic Modeling. Biotechnology and Bioengineering, New York, v. 112, p. 1376-1382, 2015.

TCHUENCHE, J. M.; KHANIS, S. A.; AUGUSTO, F. B.; MPESHE, S. C. Optimal Control and Sensitivity Analysis of an Influenza Model with Treatment and vaccination. Acta Biotheoretica, Leiden, v. 59, n. 1, 2011.

ZHOU, X.; GUO, Z. Analysis of an influenza A (H1N1) epidemic model with vaccination. Arabian Journal of Mathematics, Berlin, v. 1, p. 267-282, 2012. 